\title{
Ein zweisprachiges Feld - zwei einsprachige Felder? Brünner Literatur in den 1860er und den 1920er Jahren
}

\author{
One Bilingual Field - Two Monolingual Fields? Literature of Brno \\ in the 1860 s and the 1920 s
}

Jan Budňák

\begin{abstract}
Since over a century, the narrative of Brno literature has been one based on the principle of genius loci - Brno, the "Manchester of Moravia", a city of industry and proletarians "produces" industrial and proletarian literature. The - rarely questioned - problem with this unity of place and art has been that at the same time, the Czech version of this narrative excluded the literature of Brno written in German from it, and vice versa. The present paper suggests to take advantage of the theory of literary field (Bourdieu) as a tool for analyzing the literary field of the city to challenge the monolingual and monocultural approach to the history of Brno literature. Using the synchronic "cuts" of the 1860s when a new literature emerged following the easing of restrictions of Austrian magazine and book production as well as of activities of readers' and writers' associations in 1860/1861, and of the 1920s as a period of differentiated literary field(s) with popular fiction, bourgeois literature and various modernist and avantgarde groups, the paper attempts to show how the literary field(s) of Brno evolved. In the 1860s, in spite of already existing nationalist ideologies, there still was a largely unified field of Brno literature, based mainly on the fact that publishing houses operated in both languages and published parallel periodicals in German and Czech, whereas in the 1920s, this field was split in two structured monolingual segments which, however, still display numerous intersections and parallelisms.
\end{abstract}

\section{Keywords}

national philology; field theory; literary historiography; multilingual regions; left-wing literature; Czech Studies; German Studies; Moravia; Brno

Der Beitrag wird im Rahmen des GAČR-Forschungsprojektes (GA21-06511S, Dimenze interkulturality v německojazyčné kultuře meziválečné ČSR 1918-1939 na př́ikladu jejího levicového segmentu) veröffentlicht und wurde von diesem unterstützt. 
In Reaktion auf die Gestaltung der literaturgeschichtlichen Abschnitte im zweiten Band der umfangreichen Geschichte der Stadt Brünn [Dějiny města Brna] (Dřímal 1973), die in dem primär historiografischen Werk in Kapitel über die Künste integriert und auf fünf chronologische Teile verteilt sind, schrieb der tschechische marxistische Literaturhistoriker Milan Blahynka in seiner Rezension Folgendes:

Př́ští Dějiny literatury v Brně budou muset odpovědět na celou řadu otázek, které nepřímo nadhazují odstavce o literatuře v Dějinách města Brna. / Bude třeba vysvětlit, proč právě v Brně našli určitou možnost působení a rozvoje svého díla „individualističtí anarchisté“ na začátku století; pro právě Brno se stalo epicentrem našeho expresionismu v literatuře; jak právě z Brna vycházely podněty k rozvoji obraznosti v moderní české poezii; co vše znamenala literární redakce brněnského rozhlasu (Václavkovy referáty o literatuře, podněty k Nezvalově dramatické tvorbě atd.), co a proč znamenalo Brno pro rozvoj dětské literatury atd. (Blahynka 1974: 176)

Das Desiderat, auf das Blahynka hier eine so optimistische Anspielung macht, ist offensichtlich: Er formuliert Fragen, Brünner Literatur betreffend, deren Beantwortung durch die fragmentierte, unterkomplexe Darstellung der zerstreuten literaturgeschichtlichen Segmente in der Geschichte der Stadt Brünn unterbunden wurde, und den sich eine erwartete, literarisch fokalisierte Geschichte stellen müsste, zudem diese Fragen auch in der ein paar Jahre älteren, ebenfalls überdurchschnittlich voluminösen Studie Das literarische Leben in Brünn 1918-1965 [Literární život v Brně v letech 1918 až 1965] (Hájková - Kožmín - Vlašín 1966) auch keine befriedigende Antwort, so Blahynka, gefunden haben.

Die von Blahynka anvisierte Literaturgeschichte Brünns, die - wie er sagt - „ganz gewiss einmal“ in einer „selbständigen Monografie“" (Blahynka 1974: 176) vorgelegt werden wird, gibt es bis zum heutigen Tag nicht. Auch aus diesem Grund ist es noch immer sinnvoll, die Vorstellungen und Erwartungen darüber zu untersuchen, wie eine solche Aufgabe angegangen werden könnte. Was wären also in diesem Sinne die Grundpfeiler von Blahynkas Konzept der noch nicht geschriebenen Literaturgeschichte Brünns? Sein Bild ist zum einen von dem marxistischen Basis-Überbau-Konzept bestimmt, das hier allerdings auch als eine Art regionale bzw. territoriale Literaturgeschichte fungieren kann, zum anderen durch die Prämissen der nationalen Literaturgeschichtsschreibung. Diese zwei an sich kaum zu vereinbarenden Prinzipien erfahren bei Blahynka (aber bei weitem nicht nur bei ihm) eine Symbiose, die zu hinterfragen die Intention des vorliegenden Beitrags ist.

1 „[...] dojde jistě časem také k samostatnému knižnímu zpracování brněnských literárních dějin.“ 


\section{Status quo: Verkürzung von Regionalität auf Einsprachigkeit und Nationalität}

Beim ersten Punkt - dem Basis-Überbau-Modell als Grundlage für regionale Literaturgeschichte - beruft sich Blahynka auf einen weiteren Exponenten der marxistischen Literaturwissenschaft in der Tschechoslowakei der 1960er bis 1980er Jahre, Josef Hrabák, und die Forschungsfrage, mit der dieser an das Werk des führenden kommunistischen Intellektuellen der Zwischenkriegszeit Bedřich Václavek, der vorwiegend in Brünn und Olmütz tätig war, herangeht. Blahynka zitiert Hrabáks Frage: „Je některé místo, které pomáhalo určovat Václavkův lidský i vědecký profil svou sociální a kulturní atmosférou v letech největší Václavkovy tvůrčí aktivity a které působilo na jeho růst svým géniem loci?“ (Blahynka 1974: 176) Wonach hier Hrabák eigentlich sucht, wie umsichtig er das auch formuliert, ist die Widerspiegelung eines sozialen und kulturellen Milieus im Werk eines kommunistischen Intellektuellen, und es ist ohne Weiteres ersichtlich, dass mit diesem Milieu eben die Industriestadt Brünn gemeint ist, das ,mährische Manchester`, von dem aus die Lösung der Gleichung ausgehen soll, die zwischen dem ,proletarischen“ Intellektuellen und der ,proletarischen' Stadt aufgestellt wird.

Mit der Tendenz, das Spezifische der ,Brünner Literatur' von dem industriellen bzw. proletarischen Charakter der Stadt herzuleiten, stehen Blahynka und Hrabák (vgl. Hrabák 1982) allerdings keineswegs allein da. Auch dezidiert nicht-marxistische Literaturhistoriker und lokale literarisch-kritische Bezugsgrößen wie der konservative Brünner Bohemistikprofessor - und einst, vor dem Ersten Weltkrieg, von Haus aus Germanist - Arne Novák lokalisierte in seiner berühmten Studie über Brünner Kunst und Literatur Die Seele Brünns und seine Literatur [Duše Brna a jeho kultura slovesná] (Novák 1932) diese eben im industriellen Charakter der Stadt, den er allerdings wesentlich düsterer malt als der marxistische Fortschrittsoptimist in Sachen Literaturgeschichte Hrabák.

Diesem territorialen bzw. regionalen Zusammenhang zwischen Stadt und Literatur stellt sich allerdings bei Hrabák wie bei Novák - und es ist auch Blahynkas zweiter Punkt, den ich hier ansprechen will - eine sprachlich-nationale Grenzziehung in den Weg. Aus ihrer Perspektive betrachtet stellt sie sich jedoch dem territorialen Zusammenhang von Stadt und Literatur zur Seite. Dies ist bereits aus der kurzen Rezension Blahynkas ersichtlich. Die Autoren bzw. Autorinnen der zukünftigen Literaturgeschichte Brünns würden, so Blahynka, gut daran tun,

kdyby se autoři soustředili na brněnské specifikum; kdyby přehledný výklad koncipovali tak, aby názorně vyvstal „srovnávaci““ obraz „brněnské“ literatury, aby bylo jasno, za co vše vděčí Brno české literatuře (není toho málo, jen vzpomeňme na zápas o český charakter Brna atd.), a naopak, co vše dalo Brno české kultuře, zvláště české pokrokové a socialistické kultuře. (Blahynka 1974: 176, Hervorhebungen durch Kursivschrift JB)

Blahynka klammert hier von der eben aufgestellten Gleichung zwischen dem ,spezifisch proletarischen Ort ' und dem ,spezifisch proletarischen Text', die dem Genius loci-Topos zugrunde liegt, zunächst einmal die nicht-fortschrittliche, nicht-sozialistische Literatur 
aus - wenn auch auf eine durchlässige Art und Weise -, und vor allem - in diesem Fall jedoch apriorisch - schließt er die deutschsprachige Literatur der Stadt aus dieser Gleichung aus. Dies tut er - genauso wie Novák im Jahre 1932 und Hrabák im Jahre 1982 - durch zwei komplementäre Strategien: zum einen kommt diese ,zweite‘ Literatur der Stadt als analytischer Gegenstand gar nicht vor, sie wird nicht repräsentiert; zum anderen wird aber dieser ,Nullsignifikat' der tschechischsprachigen Kultur bzw. Literatur entgegengestellt. Somit wird die nicht repräsentierte deutschsprachige Kultur bzw. Literatur Brünns von dem eben gezeichneten Grundriss der ,industriellen“ bzw. ,proletarischen“ Literatur der Stadt ausgenommen.

Für diesen verkürzenden Denkautomatismus könnte aus heutiger Sicht die Unzulässigkeit, die ,Salon-Unfähigkeit” der (,sudetendeutschen') deutschsprachigen Literatur im (nicht nur akademischen) Diskurs der Normalisierungszeit verantwortlich gemacht werden, oder einfach das Abhandengekommensein von kollektiver Erinnerung der Region an ihre nicht mehr existente anderssprachige Kultur und deren Träger*innen. Dies scheint aber nicht der Fall zu sein, da auch Arne Novák, der bei Gott kein marxistischer Fortschrittsoptimist und Freund von proletarischer Kultur war, sich in seinem Essay von der Seele Brünns (Novák 1932) eines ähnlichen Ausschlussverfahrens der deutschsprachigen Kultur aus der ,Seele Brünns‘ bedient. In Nováks Zeit war das ,deutsche Brünn` gewiss keine abhandengekommene Erinnerung, und es war auch noch keine durch diktatorische Staatsmacht erhärtete Verdrängung dieser Erinnerung vorhanden wie in der Zeit Hrabáks und Blahynkas. Trotzdem spricht auch schon Novák von einer „agonalen“ Beziehung zwischen den beiden von ihm als einsprachig vorausgesetzten Kulturen bzw. Literaturen:

Básnická kultura Brna nemá ani děl ani osobností, jež by se mohly měřiti s Leošem Janáčkem; může se ostatně chlubiti minulostí zcela kratičkou. [...] Jeť české kulturní Brno město zcela mladičké, téměř bez tradice, které se teprve hledá a nad to opojeno dneškem, zapomíná včerejška, jenž byl chudý a šedivý. [...] živel německý, velmi sebevědomý, brání se stále tomu, aby s českým Brnem vstoupil v agón, jehož účastníci se navzájem plně a klidně uznávají. / Ale přepadnou-li v něm pracovníky ducha úzkosti, stačí prostě, aby seznali, čím bylo Brno před dvaceti roky a čím jest dnes: z provinciálního města na samém obvodu českého živlu a se stálou ctižádostí býti pouhým předměstím Vídně, se změnilo $\mathrm{v}$ jedno z hlavních středisk kulturního života v samém srdci národního státu Československého. (Novák 1932: 53-61)

Die von Novák wiederholt benutzten Figuren des Neuanfangs bzw. der Diskontinuität lassen unschwer erraten, dass auch er nur ,ein‘ Brünn zur Kenntnis nehmen will - das junge, industrielle und tschechische bzw. tschechoslowakische. Jeweilige deutschsprachige Kultur der Stadt wird ,ent-ortet“ („Vorort von Wien“) und somit vom Anspruch, an der Seele Brünns teilzuhaben oder sie mitzugestalten, ausgeschlossen.

Zusammenfassend gesagt verkürzen Novák, Hrabák und Blahynka die - wie immer aufgefasste oder bewertete - Territorialität bzw. Regionalität in kulturellen und literarischen Angelegenheiten auf Einsprachigkeit und Nationalität. Sie tun dies ohne über diese Verkürzung zu reflektieren oder sich damit explizit auseinanderzusetzen, und ste- 
hen auch mit dem Automatismus bei weitem nicht allein da, sondern repräsentieren eine nahezu allumfassende Tendenz der Literaturgeschichtsschreibung. Somit stellt sich mit großer Dringlichkeit die Frage nach alternativen Herangehensweisen an literaturgeschichtliche Phänomene in gemischtsprachlichen Regionen (vgl. Voda-Eschgfäller Horňáček 2012), die sich nicht nur von den Automatismen der nationalphilologischen Auffassung von Literaturgeschichte losmachen könnten, sondern die Literatur in beiden Sprachen in einem gemeinsamen Zusammenhang sichten und darstellen würden. ${ }^{2}$

\section{Feldtheorie als Provokation der (einsprachigen) Literaturgeschichte}

Bekanntermaßen bedeutete für Hans Robert Jauß im Jahre 1967 die von ihm vorgeschlagene Mitberücksichtigung des ,Lesers“ als Akteur und Mitgestalter von Literaturgeschichte eine „Provokation der Literaturwissenschaft“ (Jauß 1967). Eine Provokation war das in dem Sinne, dass die Literaturgeschichte durch diesen turn dazu gezwungen wurde bzw. würde, zwei eingeübte Auffassungen aufzugeben, nämlich die marxistische, in der die Literaturgeschichte, die Autor*innen und Leser*innen als Funktionen der jeweiligen sozialen Konstellation angesehen werden, die von vornherein bekannt ist, und die formalistische (Emil Staiger), die die ,ewige‘, künstlerische Bedeutung einzelner Texte aus ihrer ,Struktur' oder durch ,Einfühlungshermeneutik“ (Wilhelm Dilthey) bestimmen möchte. Auch die zweitere Herangehensweise an literarische Texte hält Jauß für zirkulär: Auch hier werde das gefunden, was man von vornherein gesucht habe.

Diese beiden Auffassungen, lautet Jauß' Vorwurf, vernachlässigen die prozesshafte, kommunikative Dimension der Literaturgeschichte, indem sie den immerwährenden Verlauf von literarischer Sinnproduktion, von Reaktionen durch Text und durch Verstehen von Texten seines kontinuierlichen Charakters berauben. Eben diese Bande gilt es nach Jauss wieder anzuknüpfen, indem die literarische Sinnproduktion durch Schreiben und Lesen von Literatur in synchronen ,Schnitten“ in ihrer jeweiligen Interdependenzen gezeigt wird.

Für die im vorliegenden Beitrag anvisierten literaturhistorischen Konstellationen Brünn der 1860er und der 1920er Jahre - soll mit analogischem Anspruch, die literaturhistorische Betrachtung einer gemischtsprachigen Region auf eine neue Grundlage zu stellen, die Feldtheorie (Bourdieu 2001) auf ihre Praktikabilität als Beschreibungsinstrument hin erprobt werden. Gegenüber dem monolingual und mononational verkürzten ,Genius loci'-Zugang Hrabáks und Blahynkas hat sie zunächst den Vorteil, dass sie primär nicht von soziokulturellen Gegebenheiten ausgeht, sondern das literarische Feld als ein „originär literarisches Bedingungsgefüge [...] zu rekonstruieren“ (Stiemer 2020: 9) ${ }^{3}$

2 Fairerweise muss ergänzt werden, dass auch die germanistischen Darstellungen, die allerdings älteren Datums sind (z.B. Szegeda 1923, Gajdeczka 1932), nach dem ,nationalphilologischen‘ Prinzip der Einsprachigkeit verfahren. In Zwischenkriegszeit gab es auch Versuche, die ,tschechoslowakischen Literaturen' gemeinsam darzustellen, diese Gemeinsamkeit wurde allerdings immer als ein Nacheinander von getrennten Literaturgeschichten einzelner Sprachen realisiert (z.B. Szegeda 1936, Novotný - Pražák 1933; vgl. dazu Hohmeyer 2002).

3 Den entscheidenden methodologischen Impuls für die Herangehensweise an regionale Literatur, die im 
versucht. Es wird als ein „sozialer Mikrokosmos der literarischen Produzenten und Institutionen“ (ebd.) betrachtet, die in Brünn sowohl in den 1860er, als auch in den 1920er Jahren in Deutsch und Tschechisch tätig waren - mit verschiedenen ,Gravitationspunkten' und deren Überschneidungen. Dies ist strenggenommen keine ,interkulturelle‘ Literaturgeschichtsschreibung, denn sie geht nicht primär dem „Widerstreit der Nationen [und] diverse[n] kulturelle[n] Überschneidungen, Verflechtungen und Ambivalenzen“ (ebd.) nach, sondern betrachtet das ,System Literatur' zunächst als die im regionalen (d.h. Brünner) „Literaturleben herrschenden Regularitäten, Machtverhältnisse und poetologische Wertmaßstäbe sowie die Strategien, mit denen sich die Autoren im literarischen Feld positionieren." (ebd.)

Es ist offensichtlich, dass ein Brünner ,Literaturfeld“ in den 1860er oder auch in den 1920er Jahren nicht die Komplexität erreichen wird, die Bourdieu beim französischen literarischen Feld gegen Ende des 19. Jahrhunderts vorfindet und analysiert (tabellarisch dargestellt bei Bourdieu 2001: 199). In Brünn werden sich auch nicht die Mechanismen der Genese des französischen literarischen Feldes finden, das bei Bourdieu dadurch entsteht, dass es sich großteils verselbständigt, d.h. seine „Autonomie“ im Rahmen des Machtfeldes behaupten kann (ebd.: 83ff.), eigene Funktionsprinzipien bekommt (z.B. dass es als ein großteils eigenständiger „Markt der symbolischen Güter“ funktioniert, vgl. ebd.: 227ff.), durch eigene Repräsentanten (Baudelaire, ebd.: 103-114) präfiguriert und auch ästhetisch realisiert wird (vgl. die reine, „heteronome“ Ästhetik, vgl. ebd.: 449ff.).

Im vorliegenden Beitrag soll nicht behauptet oder darüber gestritten werden, dass Brünn ein eigenes literarisches Feld hat - oder aber zwei einsprachige. Die Feldtheorie soll ,lediglich“ im Sinne von Stiemers eben angedeuteter Analyse der pragerdeutschen Literatur als „literarischen Lebensraum“ (Stiemer 2020: 9) von Autor*innen, Leser*innen und literarischen Institutionen und dessen Gesetzmäßigkeiten als Analysewerkzeug verwendet werden, dessen besonders geschätztes Merkmal ist, dass es ,sprachenneutral ist und trotzdem ,interkulturelle ' Phänomene wahrnehmen kann. Dazu soll - am Beispiel Brünn - der vorliegende Beitrag einige einleitende Überlegungen bieten.

\section{Situation 1: 1860er Jahre - Ein Feld wird verdoppelt}

Das charakteristischste Merkmal vom Brünner Literaturbetrieb - und der Verlagslandschaft im Allgemeinen - der 1860er Jahre ist, dass die größten Verlagshäuser der Stadt - Rohrer, Buschak \& Irrgang ${ }^{4}$, Winiker, Karafiat ${ }^{5}$, Gastl, Burkart ${ }^{6}$ u. a. - das Lesepublikum beider Sprachen bedient haben. Dabei arbeitet allerdings keiner der Verlage

vorliegenden Beitrag ergriffen wird, stellt die Monographie Haimo Stiemers Das Habitat der mondblauen Maus. Eine feldtheoretische Untersuchung der pragerdeutschen Literatur (1890-1938) (Stiemer 2020) dar.

4 Alternativ, bei tschechischsprachigen Veröffentlichung auch als Bussák a Irrgang bzw. Bušák a Irrgang geschrieben.

5 Als Franz Karafiat oder František Karafiát geschrieben.

6 Wilhelm Burkart oder Vilém Burkart. 
als ein prononciert ,literarischer': Alle genannten Häuser sind Mehrspartenverlage, die vor allem Sachbücher publizieren. Die thematische Ausrichtung reicht von Bienenzucht über Lehrbücher des Tschechischen für Deutschsprachende (und tlw. auch umgekehrt) bis zu Kommentaren zu neuen Gesetzen und Verordnungen. Die in Brünn am häufigsten herausgegebenen Bücher scheinen allerdings diverse religiöse Gebrauchsbücher zu sein: Gebete, Kirchenlieder, Märtyrergeschichten, Pilgertexte oder Texte über regionale Walfahrtsorte werden von all den genannten Verlagen in großen Auflagen und mit bewundernswerter Frequenz produziert - freilich in beiden Landessprachen. Es überwiegen dabei im Rahmen der 1860er Jahre deutschsprachige Veröffentlichungen, bei einigen Verlagen deutlich, z.B. bei Buschak und Irrgang ist das Verhältnis 52 deutsch zu 8 tschechisch veröffentlichten Titel zwischen 1860 und 1869, bei anderen, z.B. Burkart, sind es aber von insgesamt 52 Titeln 30 deutschsprachige, 6 lateinische und 16 tschechischsprachige. ${ }^{7}$

Obwohl sich keiner der Brünner Verlage explizit auf Literatur konzentriert, stellen sie dennoch die primären Anlaufstellen auch für literarische Produktion dar. Separate ,literarische‘ Veröffentlichungen - im heutigen Sinne der fiktionalen Literatur - gibt es zwar nur sehr selten, und nur bei prominentesten Autoren. ${ }^{8}$ Reicher sind aber literarische Veröffentlichungen in periodisch erscheinenden Plattformen wie Zeitungen, Zeitschriften und Kalender. Von diesen Titeln gibt es in den 1860er Jahren eine bemerkenswerte Fülle. Ohne viel zu übertreiben lässt sich sagen, dass jeder größere Verlag sich mit einer Zeitung, einer (Lese-)Zeitschrift ${ }^{9}$ und einem Kalender ${ }^{10}$ versucht, die in zwei inhaltlich weitgehend unterschiedlichen, aber von der Zielgruppe und der Textsorte her fast gleichen sprachlichen Mutationen - in Deutsch und in Tschechisch - veröffentlicht werden.

Einer der wenigen literaturhistorisch erfassten Akteure, die für die Symbiose von (fiktionaler) Literatur und Tageszeitung im Brünn der 1860er Jahre kennzeichnend sind, ist Leopold Hansmann (1824-1863). Hansmann war in der einschlägigen Zeit - d.h. von 1860 bis zu seinem Tod am 7. 7. 1863 - Chefredakteur der tschechischsprachigen Zeitung Moravské noviny, die zweimal wöchentlich erschien und in dieser Zeit im Rohrer-Verlag

7 Diese Informationen entnehme ich Recherchen im Katalog der Mährischen Landesbibliothek (vufind. mzk.cz).

8 Eines der seltenen Beispiele stellen die drei Gedichtbände des hohen Brünner Beamten und (geadelten) Landesrats Joseph C. von Wieser (18113-1886) dar, die zwischen 1860 und 1869 bei Gastl (1860: Nesseln, Epigramme), Karafiat (1863: Welehrad, Gedichte) und Břeža (1869: Gedichte) erschienen sind. Besonders der Liederkranz in zwei Büchern (UT) Welehrad ist für die landespatriotische, katholisch-habsburgische Ausrichtung der damaligen ,high-brow'-Literatur Brünns kennzeichnend. Sprache und Nation, die in dieser Konstellation trennend wirken, werden von Wieser der religiös, territorial und dynastisch begründeten Einheit „aller Mährersöhne“ (Wieser 1863: 8) eindeutig untergeordnet. Wieser schrieb ebenfalls Dramen, die allerdings keine mährischen Stoffe bearbeiteten, sondern vornehmlich aus antiken Quellen schöpften. Es handelte sich dabei um Trauer- sowie Lustspiele.

9 Bei Buschak/Bušák \& Irrgang sind die Lesezeitschriften (des ,Gartenlaube‘-Typs) Lese-Stübchen (1860$1865)$ bzw. Neues Lese-Stübchen (1866-1867) in Deutsch, sowie Besídka čtenářská. Obrázkový spis pro milovniky poučného a zábavného čtení (1862-1867) in Tschechisch. (Die Titel sind als Synonyme zu verstehen).

10 Bei Winiker ist bspw. sowohl das zwischen 1857-1863 von Hansmann redigierte Kalender Nejnovějši moravskoslezský domácí prítel (1841-1908), als auch dessen deutschsprachige Variante Neuester mährischer und schlesischer Hausfreund für Stadt und Land (1842-1906) erschienen. (Titel sind synonym). 
herausgegeben wurde. ${ }^{11}$ Leopold Hansmann publizierte in dieser Zeitung - unter der Chiffre A. D. oder dem Pseudonym Antoš Dohnal - auch mehrere Dorfgeschichten, die im hannakischen Dialekt verfasst wurden (Skalička 1987, Fišer 1993) und sich ganz offensichtlich großer Beliebtheit bei den Leser*innen der Moravské noviny erfreut haben, da sie z.B. als ein wesentlicher Faktor bei Abonnement-Werbungen in Anschlag gebracht werden.

Interessant ist, dass Hansmann/Dohnal seine Dorferzählungen, genaugenommen deren stellenweise Derbheit, explizit in Zusammenhang mit dem „reinen slawischen Leben in Mähren" bringt, das er dadurch treu abzubilden glaubt. In einer Polemik gegen ein Prager katholisches Blatt (Pozor) meint er, dass wenn jemand seine Erzählungen und Figuren derb nennt, nennt er damit alle Slawen derb - und das, so Hansmann/Dohnal, wird doch niemandes Absicht sein:

Víš, bohaprázdný hubaři, že nazvav selskou povídku sprostou, vyhlásils i všecky Slovany za sprostáky? Ty vyvaluješ oči, divže ti nevylezou, a já zase pravím: Ano, ano, tak tomu jest, mudrci můj! Pověz mně, kdepak máme až posud ještě ryzí život slovanský na Moravě, nebo o Čechách nemluvím, dobře věda, že jsou příčinlivější nežli my, a proto taky ve všem před námi, ale jářku na Moravě? Nikde jinde nežli na dědině. V Brně, v Olomouci, v Př..., drž hubu a neplácej, tam několik těch probuzených Slovanů žijou jako poustevníci ve svých komůrkách a bolestně rodí, z čeho se teprv má utvořit ten vyšší, jářku, vzdělanější náš život veřejný. Ti, co se tak nafukují, jako by u nás už všecko bylo hotové a jako by nebylo zapotřebí nežli nějakého paragrafu, aby najednou v našich palácech mezi pánami a paničkami dosavadní způsob života se proměnil v čistě slovanský, to jsou komedianti, ti šálí sebe a lid. Na prstech můžeme ve všech městách ty rodiny spočítat, kde pantáta, panímáma a děti už vědí, že jsou Slovani, a podle toho se chovají. Jak má tedy už včil z toho vyrůst povídka? (Dohnal in: Skalička 1987: 243)

Aus dieser Polemik Hansmanns/Dohnals geht deutlich hervor, dass er seine literarische Autorschaft im Hinblick auf Thematik sowie auf Poetik dem ,slawischen“ Gedanken unterordnet. Er schreibt Dorfgeschichten, und er schreibt sie ,derb` und im Dialekt, weil er sich als Autor die Aufgabe stellt, „das slawische Leben“, d.h. ein kulturelles Leben in der „mährischen“ Sprache, wie er sagt (d.h. auf Tschechisch), auch in den Städten dadurch zu fördern. Diesem Ziel ist Hansmann jedoch nicht nur durch das Verfassen von hannakischen Dorfgeschichten nachgegangen, sondern auch durch die - weniger intensive - Produktion von Geschichtsdramen, die ,slawische Stoffe‘ aufgegriffen haben. Für sein erstes slawisch-mährisches Geschichtsdrama Jaroslav ze Šternberka, vitěz nad Mongoly u Holomouce erhielt er 1857 den durch Ferdinand Fingerhut/Náprstek gestifteten Preis für historische Dramen, und nahm 1860 an dem Wettbewerb mit dem Drama Zdirad nochmal teil.

Obwohl Hansmanns/Dohnals Intention eine ,slawische“ ist, vertritt er dennoch den Redakteurposten in einer im Rohrer-Verlag herausgegebenen Zeitung. Das ist allerdings nur aus heutiger Sicht ein Widerspruch: Die deutschnational-liberale Wende lag nicht

11 Die erste Nummer dieser Zeitung ist am 1. November 1848 unter der Redaktion von F. M. Klácel und A. V. Šembera erschienen und wurde im Winiker-Verlag herausgegeben. 
nur dem Verlagshaus, sondern der ganzen Brünner Gesellschaft noch bevor. Obwohl die überwiegende Mehrheit der Titel, die im Rohrer-Verlag in den 1860er Jahren erschienen sind, deutschsprachig war, ${ }^{12}$ ist das Engagement des Verlegers auch für tschechischsprachige Zeitungen (mit Redakteuren, die ein ,slawisches‘ Programm verfolgten wie Hansmann/Dohnal) nichts weniger als ungeschmälert.

Dies lässt sich eindeutig der Reaktion der Verlegers auf den frühen Tod seiner Redakteurs Hansmann entnehmen. Hansmann ist am 7. Juli 1863 gestorben. An demselben Tag ist die letzte Nummer der Moravské noviny erschienen, die seinen Namen als zuständigen Redakteur anführt, und - da am 5. Juli 1863 das tausendjährige Jubiläum der Ankunft von Cyrill und Method in Mähren gefeiert wurde -, und mit einer dekorativ ausgestatteten, lateinisch-historisierenden ,Box‘ beginnt:

5. červenec. Na Velehradě přivítali vás otcové naši, apoštolové! bratři solunští! a vírou v Krista jsou obnoveni. Cyrille a Methoději, na věčnosti proste za nás Slovany. (Moravské noviny 1863, Jg. XV., Nr. 54., 7. Juli, S. 1)

An derselben privilegierten Stelle in der darauffolgenden Nummer der Zeitung steht schon die Todesanzeige Hansmanns, mit der Unterschrift Rudolf M. Rohrers, der gleichzeitig auch die Redakteurspflichten in Moravské noviny von Hansmann übernimmt, und wird im bewegten Ton abgefasst:

Vydavatel a nakladatel těchto novin podává ctěnému čtenářstvu a všem, jenž jsou nakloněni uvážiti zásluhy a okolnosti prŕćčinlivých vlastimilů a je zachovati v laskavé poměti, smutnou zprávu, že dne 7. července osiřely „Moravské noviny“; nebot zemřel pořadatel jejich, věrný až do posledního dne redaktor jejich, pan Leopold Hansmann. Na věčném světle jest duch jeho, a památka zásluh jeho ostaň mezi námi navždy. Rudolf M. Rohrer. (Moravské noviny 1863, Jg. XV, Nr. 55, 10. Juli, S. 1)

Aus dem flüchtigen Einblick in das literarische Feld Brünns der 1860er Jahre gehen folgende Hypothesen hervor, die durch weitere Studien überprüft bzw. präzisiert werden müssten:

1. Die Institutionalisierung der literarischen Produktion ist an Verlagshäuser gebunden, die a. keine literarische Spezialisierung erkennen lassen, und b. in beiden Landessprachen parallel agieren, obgleich die deutschsprachige Produktion quantitativ betrachtet Vorrang hat.

2. (Fiktionale) Literatur wird nicht primär in separaten Publikationen veröffentlicht, sondern in Zeitungen, (Lese-)Zeitschriften, Kalendern. Die Formate dieser Textsorten werden von einer Sprache in die andere übernommen und existieren in struktureller, aber nicht unbedingt inhaltlicher Parallelität.

12 Von den etwa 90 Titeln, die laut dem Katalog der Mährischen Landesbibliothek bei Rohrer in den 1860er Jahren erschienen, waren knapp 20 tschechischsprachig. 
3. Obwohl sich die Produzenten von Literatur bereits oft als „Slawen“, „slawische Mährer“13 oder „deutsche Mährer/Österreicher"14 positionieren, sind diese ,Identitäten“ insofern durchlässig, dass sie ihre Träger am Mitwirken im zweisprachig fungierenden Literatur- und Zeitungsbetrieb der Stadt nicht hindern. Die ,Vertextung“ des tausendjährigen Jubiläums der ,Glaubensbringer‘ Cyrill und Methods im Sommer 1863 zeigt auch, dass es zu dieser Zeit (noch) auch literarisch wirksame, regionale Anhaltspunkte eines übernationalen ,Moravismus‘ gab.

4. Textsorten wie historische Dramen und Dorferzählungen, die in beiden Landessprachen verfasst wurden, zeigen auch, dass die entstehenden einsprachigen literarischen Felder weitgehende strukturelle Überlappungen aufweisen.

Insgesamt lässt sich das vorläufige Ergebnis festhalten, dass die Brünner Literaturlandschaft der 1860er Jahre als ein institutionell noch weitgehend einheitliches literarisches und journalistisches Feld betrachtet werden kann. Es kommen in ihm aber neben Tendenzen zur Vereinheitlichung (in manchen Fällen auch bei Beibehaltung der Zweisprachigkeit) auch solche Tendenzen vor, die auf ein ,slawisches Schreiben“ hinauslaufen. Nichtsdestotrotz entfaltet sich dieses Schreiben in großteils parallelen Bahnen wie das ,deutsche'. Anders gesagt: vor dem Schreiben wird zunächst das Lesen nach Sprache getrennt. Davon zeugen nicht nur die Parallelausgaben der populären Textsorten wie Lesezeitschriften oder Kalender, sondern auch die schnelle - und sich großen Zulaufs erfreuende - Gründung von zwei ,Lese-Hallen` in Brünn unmittelbar nach den Lockerungen $1860 / 1861$.

\section{Situation 2: 1920er Jahre - Zwei Felder werden (punktuell) verlinkt}

Der auffällige Unterschied zwischen dem tschechisch- und deutschsprachigen Literaturbetrieb Brünns in den 1920er Jahren ist, dass der letztere keine modernistischen bzw. avantgardistischen Gruppierungen und Publikationsplattformen aufweist. Während unter Brünner tschechischsprachigen Autor*innen und Intellektuellen um die Mitte der 1920er Jahre intensiv diskutiert wurde, ob die progressiven Kulturzeitschriften Host (1921-1929) und Pásmo (1924-1926), die die expressionistische (Literární skupina) bzw. avantgardistische (Devětsil) Autorengruppe repräsentierten, sich unter einer gemeinsamen Redaktion zusammenschließen sollen oder nicht, führt der prominente Brünner deutschsprachige Literaturkritiker Josef Gajdeczka in seiner 1928 erschienenen Broschüre Literarischer Führer durch das Schaffen deutsch-mährischer Dichter und Schriftsteller (Gajdeczka 1928) keinen Autor an, der nach 1893 geboren wurde. Auch beim Blick in die Inhaltsverzeichnisse von Host und Pásmo findet man keinen regionalen deutsch schreibenden Autor, obwohl Deutsch als Sprache vor allem in Pásmo relativ stark vertreten ist, zudem sich die Zeitschrift auch international positioniert, ihren Namen auf der

13 Vgl. neben Hansmann/Dohnal auch z.B. die Leitartikel der Olmützer tschechischsprachigen Zeitung Moravan (1862-1863).

14 Vgl. die programmatischen Gedichte aus Wiesers Welehrad (1863). 
Titelseite in französischer, deutscher, englischer und italienischer Übersetzung abdrucken lässt und den Untertitel „internationales Flugblatt“ trägt. In Pásmo gibt es zweisprachige Aufrufe (Theo van Doesburg und Karel Teige rufen 1925 zum Konstruktivistenkongress auf), tschechischsprachige Berichte über die zeitgenössische deutsche Kultur (Josef Hrdina, 1925), auf Deutsch publizierte essayistische Texte (z.B. Willy Baumeisters „Die Fläche“ oder Hans Richters „Über das Gestalten“), ja sogar in Deutsch veröffentlichte Texte tschechischer Dichter (Vítězslav Nezval: Dem Andenken Iljitsch Lenins) oder Intellektueller (Jiří Frejka: Der konstruktive Bühnenraum) (vgl. Kubíček 2010). Auch in der Zeitschrift der Literárni skupina (Host) werden regelmäßig Beiträge von deutschschreibenden Autor*innen (in tschechischer Übersetzung) publiziert. Zudem handelt es sich meistens um Text deutschböhmischer Autor*innen, die dem Expressionismus nahe standen. Im 5. Heft des 1. Jahrgangs von Host wurde der Essay Alfred Endlers ${ }^{15}(* 1897$ Reichenberg/Liberec) Svètový názor nového dramatu, im 6. Heft der Essay Identifikace a produktivni konflikt von Franz Werfel abgedruckt. Nicht zuletzt fungierte der deutsche Expressionismus sogar als eine Art Verbindungsglied zwischen dem Devětsil und der Literárni skupina (vgl. den Essay Čteni o německém expresionismu Karel Teiges in Host 1, Heft 7.-8., April 1922).

Diese Abwesenheit modernistischer bzw. avantgardistischer Tendenzen in der deutschsprachigen Literatur Brünns ist umso bemerkenswerter, als es dort bereits 1918 mit Der Mensch eine expressionistische Zeitschrift gab, die durchaus auf einem ,tschechoslowakischen' Grundriss gebaut war. Ihr Herausgeber war Brünner Industrieller Leo Reiß, der literarische spiritus rector der Zeitschrift war der junge Prager Johannes Urzidil (1896-1970), und die Zeitschrift verzichtete neben vieler junger deutschsprachiger Autoren aus Österreich, Deutschland und Prag und vieler Übersetzungen aus dem Tschechischen (Otokar Březina, Jiří Karásek ze Lvovic, Antonín Macek, Karel Čapek, J. Goll, Petr Bezruč, Jiří Mahen, František Khol) auch auf die Beiträge von Brünner Autoren nicht. Neben den tschechisch schreibenden Brünnern Mahen und Bezruč und Essays und Sonetten des Mitherausgebers Leo Reiß wurden in Der Mensch auch Texte von durchaus progressiven Brünner Autoren abgedruckt: Auszüge aus dem Zyklus Werden von Friedrich Bill (1894-1972), ${ }^{16}$ der kosmopolitische Essay Das Weltbürgertum des zukünftigen Dramaturgen des Brünner deutschen Theaters Guido Glück, frühe Gedichte von dem aus Boskovicz stammenden Hermann Ungar (1893-1929) unter dem Pseudonym Réveille), der kurz vor dem literarischen Durchbruch mit seinem ersten Erzählband Knaben und Mörder (1920) stand, oder Texte von den ein wenig älteren Brünner*innen

$15 \mathrm{Zu}$ Endler vgl. http://www.ipsl.cz/index.php?id=1142\&menu=echos\&sub=echos\&str=echos_jedno.php [23. 11. 2021]

16 Sehr interessant, und von germanistischer Forschung komplett unberücksichtigt geblieben ist sein Nachlass, der vom New Yorker Leo Baeck-Institut digitalisiert wurde und online zugänglich ist: https://archives.cjh. org/repositories/5/resources/14095 [23. 11. 2021]. Bei Bills journalistischen Beiträgen, meistens für sozialdemokratische Tageszeitungen verfasst (z.B. Brünner Volksfreund oder Wiener Arbeiter-Zeitung), steht spätestens ab 1921, allerdings der Vermerk „Friedrich Bill (Prag)“. Obwohl der Topos des ,Wegzugs' von Literaten und Intellektuellen aus der ,Provinzstadt‘ Brünn zum Grundbestand der Brünner (literatur-)historischen Imagination gehört (vgl. Sedlářová 1993: 167) und für die Beschreibung der Struktur des literarischen/intellektuellen Feldes potentiell extrem wichtig ist, ist es meines Wissens noch nie analytisch bearbeitet genommen worden. 
Walter Beamt (1890-1942) und Erika Rheinsch (1880-1967). Mit einigen erzexpressionistischen Texten ist in der Zeitschrift auch der gebürtige Brünner Ernst Weiß (18821940) vertreten. Der Mensch, der während des Jahres 1918 immerhin in drei Einzel- und vier Doppelheften erschien, stellt somit eine aus der heutigen Sicht fast ,ideal' ausgeglichene Symbiose von deutsch- und tschechischsprachiger Literatur, von Zentralität (Wien, Prag, deutscher Expressionismus) und Regionalität (Brünn), und von ästhetischer Progressivität (E. Weiss) und der ,klassischen‘ Moderne der Jahrhundertwende (Březina). Erwähnenswert ist ebenfalls die politische Tendenz des Blattes im Sinne eines expressionistischen Internationalismus, ja Kosmopolitismus, der in Brünn unmittelbar nach dem Ersten Weltkrieg durch die Kosmopolitische Gesellschaft und ihre Zeitschrift Die Wahrheit (1919-1923) aufgenommen und weiter entwickelt wurde. Somit stellt sich die Frage nach der Abwesenheit einer deutschsprachigen literarischen Avantgarde im Brünn der 1920er Jahre noch dringender.

Darüber hinaus ist beim Blick auf das tschechischsprachige literarische Feld Brünns (unter Einbeziehung von ,nationalen' und internationalen Netzwerken, in die es eingebunden war) klar, dass es sich dabei um ein weitgehend diversifiziertes Feld handelt. Dadurch kann unschwer der Eindruck entstehen, dass dieses Feld ein ,eigenes“, in sich geschlossenes Gebilde ist, das lediglich entweder ,sich von außen inspirieren lässt' (aus Böhmen, aus dem Ausland) oder selbst ,Netzwerke aufbaut‘. Die Position im Feld, die - mit Bourdieu formuliert - sich eines hohen „institutionellen Konsekrationsgrades“ (Bourdieu 2001: 200) - hielten in den 1920er Jahren die Autor*innen des Moravské kolo spisovatelů inne. Obwohl das bereits 1912 gegründete Kolo sich erst ab Mitte der 1920er Jahre zu institutionalisierten Veranstaltungen aufraffte, Monographien zu mährischen Autoren herausgab, einen Gemeinschaftsverlag gründete und erst ab Anfang der 30er Jahre eine literarische Revue veröffentlichte (Kolo), handelt es sich dabei um einen Zusammenschluss ,verdienter 'Autoren, die im kulturellen bzw. intellektuellen Leben der Stadt privilegierte Posten innehaten (K. Elgart Sokol war Schuldirektor, Theaterkritiker, J. Marcha war Abgeordneter und Senator, der dem Kolo nahestehende J. Mahen war Kulturkritiker, Dramaturg des tschechischen Theaters und Bibliotheksdirektor). (vgl. Hájková - Kožmín - Vlašín 1966: 318ff.) Im Avantgardesegment der Brünner tschechischsprachigen Literatur war mit dem Brünner Devětsil der explizit marxistische, mit Literárni skupina der weniger politische Teilbereich besetzt (vgl. ebd.: 304ff.), der den Anschluss auf deutschen Expressionismus und französischen Unanimismus gesucht hat bzw. deren Weiterführung im Sinne des Pazifismus und der sozialen Dichtung. Darüber hinaus entwickeln beide Gruppierungen neben ihrer kollektiven Publikationstätigkeit (Zeitschriften Pásmo und Host) auch eine reichhaltige Öffentlichkeitsarbeit, und zwar nicht nur in Brünn selbst, sondern in regionalen Zentren in ganz Mähren. Die Vortragstätigkeit der beiden avantgardistischen Gruppierungen war auch beeindruckend.

Trotz des scheinbar hermetischen Charakters der beiden Brünner einsprachigen Felder gab es vereinzelt auch nachweisbare gegenseitige Durchdringungen, die nicht als ,Entlehnungen' aus Böhmen oder aus dem Ausland zu verstehen sind, sondern als Ergebnisse von lokalen Netzwerken. Ein solches Beispiel stellt die überhaupt erste in Buchform publizierte Arbeit des berühmten (Brünner) tschechischen Dichters František Halas (1901-1949). 
Mitte der 1920er Jahre war Halas einer der aktivsten Mitglieder des Brünner Devětsil und neben Vítězslav Nezval und Jaroslav Seifert auch einer der produktivsten Lyriker, die für ihre Zeitschrift Pásmo geschrieben haben. (Pichlová 2006: 37) Zum ,gedruckten' Autor ist Halas allerdings nicht mit seiner Lyrik geworden, sondern als Übersetzer des Einakters Pohádka lásky von Otto Sonnenfeld (1898-1966). Der Einakter wurde auch am 13. Juni 1926 auch im Brünner tschechischen Theater Na Veveř́ aufgeführt und durch eine heitere Rezension in der Brünner Tageszeitung Lidové noviny ,beehrt‘ worden:

[...] „Pohádka lásky“ je od ředitele brněnského Slaviafilmu pana Sonnenfelda, a je tedy aspoň místním původem zajímavá. Přivábila hojně německého obecenstva. jemuž byla jakousi společenskou událostí; byla jím velmi srdečně aklamována. Sama o sobě je to aktová hříčka, starosvětsky prozrazující svou jedinou zápletku, na níž tedy patrně nechce stavět úspěch. (E. S. [vermutlich Karel Elgart Sokol] 1926)

Aus der Rezension erfahren wir, dass Otto Sonnenfeld - zu dem es auch keine historiographische oder germanistische Literatur gibt ${ }^{17}$ - Direktor der produktiven Brünner Filmgesellschaft Slaviafilm war (Polák 2016), dass sein Stück eher als ein symbolischer ,interkultureller" Akt wahrgenommen wurde, und dass es keinerlei avantgardistische Tendenz erkennen lässt, wie sich vielleicht anhand des Umstands, dass es von dem jungen Halas übersetzt wurde, annehmen ließe. Nichtsdestotrotz kann diese Episode als eine punktuelle Verknotung der scheinbar auseinanderentwickelten literarischen Felder Brünns, die durch pragmatische Motive und regionale Nähe motiviert war. ${ }^{18}$

Ein anderes Beispiel von gleichzeitiger Kon- und Divergenz der einsprachigen literarischen Felder Brünns lässt sich mit dem relativ reichhaltigen Brünner Engagement des Schriftstellers und Redakteurs Friedrich Soukup (geb. 1899 in Brünn - verst. nach 1948) aufs Tapet bringen. Soukup, so merkwürdig das im Lichte seiner späteren Tätigkeit für das NS-Regime klingen mag (vgl. in belletrisierter Form bei Tučková 2012; deutsch 2015), stellt nämlich am ehesten das dar, was sich als brünnerdeutscher avantgardistischer Schriftsteller bezeichnen ließe. Dabei ist gerade seine Trajektorie im literarischen Feld der Region kennzeichnend: Soukup hat 1918 mit einem bei Georg Karafiat in Brünn herausgegebenen umfangreichen expressionistischen Gedichtband debütiert (Soukup 1918), auf den 1923 ein zweiter mit ähnlicher Poetik folgte (Soukup 1923). Soukups frühe Texte sind ein Beleg dafür, dass der ausgehende Expressionismus in Brünn auch auf literarische Produktion Einfluss hatte, die sich der Zeitschrift Der Mensch (1918) und den expressionistischen Aufführungen im Brünner deutschen Theater (vgl. Wessely 2011: 117ff.) unter der Direktion Rudolf Beers (1918-1921) gewissermaßen zur Seite stellte.

17 Sogar in einer Brünner Bachelorarbeit, die sich mit dem Slaviafilm in der Stummfilmära auseinandersetzt, kommt sein Name nicht vor (Polák 2016). Recherchierbar ist nur sein Engagement im tschechoslowakischen Exilkorps während des Zweiten Weltkriegs. Für Slaviafilm hat er offensichtlich bis in die 1930er Jahre hinein gearbeitet (https://encyklopedie.brna.cz/home-mmb/?acc=profil_osobnosti\&load=22489, [23. 11. 2021]).

18 Sonnenfeld schrieb ab 1920 zahlreiche Theaterkritiken über Brünner tschechische und deutsche Vorstellungen für die Zeitschrift der Brünner Kosmopolitischen Gesellschaft, die Wahrheit (1919-1923), die programmatisch über kulturelle Veranstaltungen in beiden Sprachen berichtete und dies auch essayistisch breit reflektierte. 
Friedrich Soukup ist für das Brünner (deutsche) literarische Feld auch aus ,institutioneller' Perspektive in zweifacher Hinsicht interessant: Er gehört zu den rührigsten Akteuren (und zum Vorstand) der zwischen 1919 und 1924 in Brünn wirkenden Literarischen Gesellschaft ${ }^{19}$, die viele Vortragsabende zu moderner Literatur (August Strindberg, Oscar Wilde, Hanns Heinz Ewers, Hugo Salus, Emil Lucka, Anton Wildgans), aber einige auch zur jüngsten Literatur Brünns (Friedrich Soukup, Fred A. Angermayer, Karl Norbert Mrasek, Karl Kreisler, vgl. Tagesbote aus Mähren und Schlesien, 12. 10. 1919, S. 7). Ihre Vermittlungstätigkeit war dabei explizit auf „moderne Literatur“20 ausgerichtet (vgl. Tagesbote aus Mähren und Schlesien, 12. 4. 1920, S. 4), anhand der Autorennamen ist aber erkennbar, dass die Literarische Gesellschaft nicht gezielt expressionistisch und schon gar nicht avantgardistisch ausgerichtet war.

Darüber hinaus ist Soukup Herausgeber, Redakteur und aktivster Autor der 1924 bis 1926 in Brünn herausgegebenen Zeitschrift Elite, deren Programm sich den Brünner tschechischen avantgardistischen Zeitschriften der 20er Jahre zunächst durchaus analogisch liest:

Wir haben die Spalten unserer Zeitschrift willig der literarischen, verheißungsvollen Jugend eröffnet, denn nur von dieser ist Gutes, Kräftiges, Ideal-Revolutionäres zu erwarten, niemals aber von der flügellahmen doktrinären Literaturfexerei. (Tagesbote aus Mähren und Schlesien, 12. 7. 1924 , S. 6)

Soukup verfolgte mit dieser reich ausgestalteten Kunst- und Kulturzeitschrift durchaus das Ziel, auf lokale Kunst bzw. Literatur zurückzugreifen, was ihm bei der bildenden Kunst auch gelang (Samuel Brunner), obgleich die Progressivität eher dem Layout der Zeitschrift (z.B. ihrem quadratischen Format) anzumerken war. Die junge lokale Literatur vertrat in der Zeitschrift zwar fast ausschließlich Soukup selbst: In den ersten sieben Heften der Elite druckte er seinen Roman Weltlüge in Fortsetzungen ab und gab ihn gleich darauf im „Verlag der Elite“ in Buchform heraus (Soukup 1924). Er konnte dort aber auch einige - bis auf Karl Norbert Mrasek - heute unbekannte und schwer ermittelbare jüngere Brünner Autoren unterbringen, z.B. Felix Langer (1889-1979, vgl. BellachMulterer 2003) oder Robert (Maria) Oehler usf. Immerhin gelingt es aber Soukup, zwei Jahre lang das lokale Kultur- und Literaturpublikum mit modern ausgestatteten Theater-, Konzert- und Sportberichten, Essays zu aktuellen Themen (z.B. Sport, Messen) und

19 Vgl. Archivbestand zur Literarischen Gesellschaft im Mährischen Landesarchiv, Fonds der Polizeidirektion Brünn B26, Karton 2540, Signatur 1082. Zum Vorstand gehören neben Soukup z.B. auch der Dramaturg des Brünner deutschen Theaters Robert Pirk oder der Buchhändler Ernst Wiener. Präsident der Literarischen Gesellschaft war Bruno Hinkelmann.

20 „Dr. K. K. [d.i. Karl Kreisler] - Die ,Literarische Gesellschaft', eine noch junge Vereinigung, die mit gröBerem oder geringerem Erfolge, aber einem Eifer der aller Anerkennung wert ist, sich bemüht, Interesse für moderne Literatur in weiteren Kreisen zu wecken, und in der richtigen Erkenntnis, daß man sich dem Tieferen der Dichtung nicht näher fühlt als wenn sie sich aus dem lebendigen Wort dessen, der sie schuf, darstellt, lädt Schaffende ein, vor einem Publikum aus ihren Werken zu lesen. Salus, Lucke lernte man so kennen und nun, am letzten Samstag, in aufsteigender Linie, Anton Wildgans.“ (Tagesbote aus Mähren und Schlesien, 12.4. 1920, S. 4). 
durchaus progressiver zeitgenössischer Literatur zu bedienen: Franz Theodor Csokor, Hanns Heinz Ewers usf. Soukup ist es schließlich sogar gelungen, am 28. Februar 1926 in Brünn das bereits 1904 aufgelöste politische Münchner Kabarett Die elf Scharfrichter „aus der Versenkung wieder erstehen zu lassen.“ (Tagesbote aus Mähren und Schlesien, 1. 3. 1926, S. 3) Soukup selbst las dabei Gedichte von Klabund, Mühsam und Wedekind und „erntete besonders durch sein eigenes Gedicht ,Der Selbstmörder“ wohlverdienten reichen Beifall.“ (ebd.)

\section{Fazit}

Die zuletzt vorgestellten Fallbeispiele - Der Mensch und Friedrich Bill; Die Wahrheit, Otto Sonnenfeld und František Halas; und schließlich die Literarische Gesellschaft, die Elite und Friedrich Soukup - deuten darauf hin, dass die Hypothese von der Absenz einer jungen, progressiven Literatur im Brünner (deutschen) literarischen Feld der 1920er Jahre einer näheren Untersuchung unterzogen werden sollte. Junge Literatur` war da und sie konnte ihren Ort im literarischen Feld auch institutionell behaupten: als öffentlich aktive Vereinigung und anspruchsvolle Zeitschrift. Einer Untersuchung wert wäre sich auch die Frage, wie sich in den zwei ,einsprachigen“ Literaturbetreiben avantgardistische Schreibweisen und Autorschaftskonzepte appropriieren und wie diese mit denen der ,klassischen Moderne‘ bzw. des Expressionismus interagieren. Zumindest punktuell lässt sich aber schlussfolgern, dass es auch zu Kontaktzonen zwischen tschechisch- und deutschsprachiger Literaturszene der Stadt kommt.

Aus dem vorliegenden Beitrag dürfte auch nicht zuletzt der Bedarf nach einer feldanalytisch angelegten Untersuchung von mehrsprachigen literarischen Räumen bzw. Regionen hervorgegangen sein. Der kontrastierend-synchrone Blick auf zwei "Situationen“ der Brünner Literatur, der hier angestrebt wurde, dürfte deutlich gemacht haben, dass die Betrachtung der ,einen“ Literatur ohne die ,andere‘ viel ärmer ausfallen muss und eine wesentliche Lücke hinterlässt, die der kulturhistorischen Situation nicht entspricht. Ob die im Titel des Beitrags angedeutete Hypothese von dem einen, sich verdoppelnden Feld der 1860er Jahre und den punktuell verlinkten zwei Feldern der 1920er Jahre einer gründlicheren Untersuchung standhält, wird sich „ganz gewiss einmal“, und vielleicht auch in einer „selbständigen Monographie“ (Blahynka) zeigen.

\section{Quellen}

Bellach-Multerer, Doris (2003): Felix Langer: Leben und Werk eines deutschsprachigen Dichters aus Brünn. Diss., Wien.

Blahynka, Milan (1974): Literární Brno 1850-1965. In: Česká literatura 22: 2, S. 175-177.

Bourdieu, Pierre (2001): Die Regeln der Kunst. Genese und Struktur des literarischen Feldes. Frankfurt/Main: Suhrkamp.

Dřímal, Jaroslav - Peša, Václav (1973) (hrsg.): Dějiny města Brna 2. Národní výbor města Brna Blok. 
Fišer, Zdeněk (1993): Leopold Hansmann. Kroměříž: Muzeum Kroměřížska.

Gajdeczka, Josef (1928): Literarischer Führer durch das Schaffen deutsch-mährischer Dichter und Schriftsteller. Brünn: Josef Klär.

Hájková, Alena - Kožmín, Zdeněk - Vlašín, Štěpán (1966): Literární život v Brně v letech 1918 až 1965. In: Brno v minulosti a dnes VIII, S. 301-369.

Hohmeyer, Andrea (2002): „Böhmischen Volkes Weisen“. Die Darstellung der deutschsprachigen Dichtung in den böhmischen Ländern der Jahre 1895 bis 1945. Münster: LIT.

Hrabák, Josef (1982): Z dějin ,brněnského románu‘. In: ders: Život s literaturou. Brno: Blok, S. 98-111.

Jauß, Hans Robert (1967): Literaturgeschichte als Provokation der Literaturwissenschaft. Konstanz: Universitätsverlag.

Kubíček, Jaromír - Šimeček, Zdeněk (2001): Noviny a časopisy na Moravě a ve Slezsku do roku 1918. Literatura a prameny, sbírky, bibliografie. Brno: Moravská zemská knihovna.

Kubíček, Jaromír (2010) (hrsg.): Pásmo 1924-1926. Index 1929-1939. Brno: Moravská zemská knihovna.

Novák, Arne (1932): Duše Brna a jeho kultura slovesná. Brno: Moravští bibliofilové a exlibristé.

Novotný, Miloslav - Pražák, Albert (1933) (hrsg.): Československá vlastivěda. Díl VII, Písemnictví. Praha: Sfinx.

Pichlová, Petra (2006): Neznámá literární tvorba Františka Halase. In: Host 2006/8, S. 37-40.

Polák, Ivan (2016): Slaviafilm napříč obdobím němého filmu. MU Brno (Bachelorarbeit), https:/ / is.muni.cz/th/xndwg/Slaviafilm_Nejista_sezona_final.pdf [23. 11. 2021]

Sedlářová, Jitka (1993): Německá kultura v Brně 1918-1938. In: Bulletin Moravské galerie v Brně. Brno: MG, S. 167-170.

Skalička, Jiří (1987): Proč Staré hanácké povídky Antoše Dohnala? In: Dohnal, Antoš: Staré hanácké povídky. Ostrava: Profil, S. 234-249.

Sonnenfeld, Otto (1926): Pohádka lásky. Brno-Juliánov: Devětsil.

Soukup, Friedrich (1918): Dichtungen. Brünn: Karafiat.

Soukup, Friedrich (1923): Extase des Erwachens. Gedichte. Cassel: Max Ahnert.

Soukup, Friedrich (1924): Weltlüge. Roman. Brünn: Verlag der Elite.

Stiemer, Haimo (2020): Das Habitat der mondblauen Maus. Eine feldtheoretische Untersuchung der pragerdeutschen Literatur (1890-1938). Würzburg: Königshausen \& Neumann.

Szegeda, Wilhelm (1923): Südmährisches Schrifttum. Eine literarhistorische Darstellung. Znaim: M. F. Lenk.

Szegeda, Wilhelm (1936): Tschechoslovakische Anthologie (Chrestomathie). Beginnend mit den Heldensagen des tschechischen Volkes. Eine Auslese von Proben tschechoslovakischer Dichter und Schriftsteller von der ältesten Zeit bis in die Gegenwart. Pohrlitz - Brünn: Selbstverlag der Herausgebers.

Tučková, Kateřina (2012): Žítkovské bohyně. Brno: Host.

Tučková, Kateřina (2015): Das Vermächtnis der Göttinen. München: DVA.

Voda-Eschgfäller, Sabine - Horňáček, Milan (2012) (hrsg.): Regionalforschung zur Literatur der Moderne. Olomouc: Univerzita Palackého.

Wessely, Katharina (2011): Theater der Identität. Das Brünner deutsche Theater der Zwischenkriegszeit. Bielefeld: transcript.

Wieser, Joseph C. (1863): Welehrad. Ein Liederkranz in zwei Büchern. Brünn: Karafiat. 
Mgr. Jan Budňák, Ph.D. / budnak@phil.muni.cz

Masarykova univerzita, Filozofická fakulta, Ústav germanistiky, nordistiky a nederlandistiky Arna Nováka 1, 60200 Brno, CZ

This work can be used in accordance with the Creative Commons BY-SA 4.0 International license terms and conditions (https://creativecommons.org/licenses/by-sa/4.0/legalcode). This does not apply to works or elements (such as image or photographs) that are used in the work under a contractual license or exception or limitation to relevant rights 
